\title{
Maximum Voluntary Ventilation and Its Relationship With Clinical Outcomes in Subjects With COPD
}

\author{
Ana Carolina Andrello, Leila Donaria, Larissa A de Castro, Letícia F Belo, Lorena P Schneider, \\ Felipe VC Machado, Marcos Ribeiro, Vanessa S Probst, Nidia A Hernandes, and Fabio Pitta
}

\begin{abstract}
BACKGROUND: Previous studies have reported that maximum voluntary ventilation (MVV) may be better associated with commonly used outcomes in COPD than $\mathrm{FEV}_{1}$ and may provide information on respiratory mechanics. In this study, we aimed to investigate the relationship between MVV and clinical outcomes in COPD and to verify whether MVV predicts these outcomes better than $\mathrm{FEV}_{1}$. METHODS: We conducted a cross-sectional study involving individuals with COPD. Lung function was assessed with spirometry; maximum inspiratory and expiratory pressures ( $\mathbf{P}_{\text {Imax }}$ and $\mathbf{P}_{\text {Emax }}$, respectively) were assessed with manuvacuometry; and functional exercise capacity was assessed with the 6-min-walk test (6MWT). Dyspnea was assessed with the modified Medical Research Council (mMRC) scale; functional status was assessed with the modified Pulmonary Functional Status and Dyspnea Questionnaire (PFSDQ-m); and health status was assessed with the COPD Assessment Test (CAT). Correlations were verified with the Spearman coefficient, and stepwise multiple linear regression models investigated the predictors of clinical outcomes. RESULTS: Our study included 157 subjects: 82 males; median (interquartile range) age 66 (61-73) y; FEV 46 (33-57) \% predicted; 6MWT 86 (76-96) \% predicted; PFSDQ-m total score 34 (14-57); and CAT total score 13 (7-19). Moderate correlations were found between MVV and $P_{\operatorname{Imax}}(r=0.40)$, 6MWT $(r=0.50)$, mMRC $(r=-0.56)$, and total scores on the PFSDQ-m $(r=-0.40)$ and the CAT $(r=-0.54)$. In the regression models, MVV was a predictor of almost all clinical outcomes, unlike $\mathrm{FEV}_{1}$. CONCLUSIONS: MVV correlates moderately with clinical outcomes commonly used in the evaluation of individuals with COPD, and MVV is a better predictor of respiratory muscle strength, functional exercise capacity, and patient-reported outcomes than $\mathbf{F E V}_{\mathbf{1}}$. Key words: COPD; pulmonary function tests; spirometry; maximum voluntary ventilation; health status; exercise. [Respir Care 2021;66(1):79-86. (C) 2021 Daedalus Enterprises]
\end{abstract}

\section{Introduction}

COPD is a systemic disease caused primarily by prolonged exposure to tobacco and other harmful particles.

Drs Donaria, de Castro, Ribeiro, Hernandes, and Pitta, and Ms Andrello, Ms Belo, Ms Schneider, and Mr Machado are affiliated with the Laboratory of Research in Respiratory Physiotherapy, Physiotherapy Department, State University of Londrina, Londrina, Brazil. Dr Probst is affiliated with the Center of Research and Post-Graduation, State University of Londrina, Londrina, Brazil.

Ms Andrello, Ms Belo, and Ms Schneider are supported by the Coordination for the Improvement of Higher Education Personnel (CAPES), Brazil. Drs Probst and Pitta are supported by the National Council for Technological and Scientific Development (CNPq), Brazil. The other authors have disclosed no conflicts of interest.
COPD deeply affects the health and quality of life of patients and is the third leading cause of death worldwide..$^{1-5}$ The main pulmonary symptoms of the disease are dyspnea, chronic cough, and increased sputum production, along with extrapulmonary manifestations such as fatigue,

\footnotetext{
Ms Andrello presented a version of this paper at the 10th South Brazilian Congress of Respiratory, Cardiovascular and Intensive Care Physiotherapy (SULBRAFIR), held October 17-19, 2019, in Gramado, Rio Grande do Sul, Brazil.

Correspondence: Fabio Pitta PT PhD, Departamento de Fisioterapia - Centro de Ciências da Saúde, Hospital Universitário de Londrina, Universidade Estadual de Londrina, Avenida Robert Koch, 60 Vila Operária, 86038-350, Londrina, Paraná, Brasil. E-mail: fabiopitta@uol.com.br.
}

DOI: $10.4187 /$ respcare.07855 


\section{Maximum Voluntary Ventilation and Clinical Outcomes in COPD}

muscle dysfunction, reduction in functional exercise capacity, and sedentary lifestyle. ${ }^{2,3,6,7}$

The diagnostic confirmation of COPD is given by the clinical history along with spirometry, which quantifies $\mathrm{FVC}$ and $\mathrm{FEV}_{1} . \mathrm{FEV}_{1}$ is the variable most widely used in research and clinical practice to classify the degree of airflow obstruction in COPD, in addition to its use as a prognostic factor and in therapeutic drug response..$^{3-5}$ However, there is limited correlation of $\mathrm{FEV}_{1}$ with important patientreported outcomes in COPD. ${ }^{8-10}$ Furthermore, only a few studies have called attention to other disease markers that correlate better with these outcomes. ${ }^{11-14}$

Maximum voluntary ventilation (MVV) is a spirometric parameter that is not commonly explored in the scientific literature. Recently, with the emergence of new methods of lung function assessment, it has been explored even less. MVV evaluates the maximum amount of air a person can inhale and exhale voluntarily in a given period of time. This measure provides information on respiratory muscle mechanics and endurance, which are involved in the mechanism of dyspnea and exercise limitation. ${ }^{15-18}$

The hypothesis tested in this study is that MVV can predict better than $\mathrm{FEV}_{1}$ the overall impairment of subjects with COPD because it reflects the overall function of the respiratory system and not just the air-flow obstruction. In this context, the objective of this study was to investigate the relationship of MVV with clinical outcomes in this population and, additionally, to verify whether MVV is a better predictor of patient-reported outcomes than $\mathrm{FEV}_{1}$.

\section{Methods}

This was a retrospective analysis of baseline-only data from a convenience sample recruited between 2016 and 2018 for inclusion in a high-intensity exercise training program at the out-patient clinics of Respiratory Therapy and Pulmonology of the State University of Londrina in Brazil. Inclusion criteria were the diagnosis of COPD according to GOLD criteria, ${ }^{3}$ clinical stability in the last 3 months before inclusion, not having participated in any rehabilitation program in the last year, and not presenting with any severe cardiovascular disease or musculoskeletal impairment that could potentially limit the tests. Exclusion criteria were the inability to perform the proposed tests or exacerbation that occurred during the evaluation protocol. The study was approved by the institution's ethics committee, and all subjects signed an informed consent form prior to any data collection.

\section{Assessments}

At the first meeting, demographic and anthropometric data were collected, as well as information on comorbidities and history of exacerbations. Additionally, subjects

\section{QUICK LOOK}

\section{Current knowledge}

Research and clinical practice commonly use $\mathrm{FEV}_{1}$ to classify the degree of air-flow obstruction in patients with COPD, to serve as prognostic factor, and to evaluate therapeutic drug response. However, there is limited correlation of $\mathrm{FEV}_{1}$ with important outcomes in COPD such as dyspnea, functional exercise capacity, and quality of life. Only a few studies have called attention to other disease markers that correlate better with these outcomes.

\section{What this paper contributes to our knowledge}

MVV correlates equally or better than $\mathrm{FEV}_{1}$ with functional and patient-reported outcomes in subjects with COPD. Additionally, MVV can reflect the ventilatory reserve available to respond to the increase in physiological demands during exertion. The results of this study reinforce the importance of this test in the comprehensive evaluation of lung function to assess the impact of physical and functional limitation in COPD.

were assessed regarding pulmonary function before and after bronchodilator use with a portable spirometer (SpirobankG, MIR, Rome, Italy) in the first 120 subjects, and plethysmography equipment (Vmax, Carefusion, Hoechberg, Germany) replaced the portable spirometer with the last 37 subjects. The protocol followed the American Thoracic Society/European Respiratory Society guidelines. ${ }^{15-19}$ Reference values were those from Pereira and Rodrigues ${ }^{20}$ for the Brazilian population. Measurements made after bronchodilator use were used for the analysis. It was not possible to perform plethysmography in the complete sample due to the unavailability of the equipment for a period of time.

The MVV maneuver was performed using the same portable spirometer or plethysmography equipment, as mentioned above. The test requires collaboration and maximum effort from the subject, which are encouraged through strong verbal encouragement. The maneuver is composed of deep, fast, and forced breathing for $12 \mathrm{~s}$ and maintaining a breathing frequency of $90-110$ breaths/min, as established by guidelines. ${ }^{15-19,23}$ Reference values were those specific for the Brazilian population according to Neder et al. ${ }^{24}$ The estimated MVV was calculated as $\left[\left(\mathrm{FEV}_{1} \times 37.5\right)+15\right]$. The MVV index was calculated as [measured $\left.\mathrm{MVV} /\left(\mathrm{FEV}_{1} \times 40\right)\right]$. This index is recommended by guidelines as an indicator of adequate effort as compared with the $\mathrm{FEV}_{1}$. An MVV index $<0.80$ indicates disturbance or poor effort of the individual. ${ }^{15}$ 


\section{MaXimum Voluntary Ventilation and Clinical Outcomes in COPD}

Respiratory muscle strength was also assessed during the first visit through maximum inspiratory and expiratory pressures ( $\mathrm{P}_{\operatorname{Imax}}$ and $\mathrm{P}_{\text {Emax }}$, respectively) with a digital manometer (MVD300, Globalmed, Porto Alegre, Brazil). Assessment was performed according to the technique described by Black and Hyatt ${ }^{22}$ and Brazilian guidelines. ${ }^{23}$ Brazilian reference values reported by Neder et $\mathrm{al}^{24}$ were used.

All tests regarding pulmonary function and respiratory muscle strength were performed with the subjects in the seated position, using a nose clip, and oriented to keep the lips well coupled to avoid leakage. Subjects kept feet supported, with hands resting on the thighs, and maintained upright posture without compensations during the execution of the maneuvers. For all tests, individuals received detailed instructions with practical demonstration and standardized verbal encouragement.

In the second visit, functional exercise capacity was assessed with the 6-min-walk test (6MWT) according to international guidelines ${ }^{25}$ and using reference values reported by Britto et $\mathrm{al}^{26}$ for the Brazilian population. Subjects were instructed to walk the farthest possible distance (without running) on a flat corridor that was $30 \mathrm{~m}$ long for $6 \mathrm{~min}$; subjects received standardized verbal encouragement every minute. Due to the learning effect, 2 tests were performed, with a minimum interval of $30 \mathrm{~min}$ between them, or until the vital signs returned to baseline. ${ }^{25}$ The test with the greatest distance was used for analysis.

The modified Medical Research Council scale $(\mathrm{mMRC})^{27,28}$ was used to assess limitation by dyspnea in daily life. The scale consists of 5 items that describe the sensation of dyspnea in daily activities and uses a scale of $0-4$, where $0=$ dyspnea triggered only in strenuous activities and $4=$ limiting dyspnea on minimal exertion or at rest.

The modified version of the Pulmonary Functional Status and Dyspnea Questionnaire (PFSDQ-m) was applied to assess functional status. The questionnaire assesses 3 domains: influence of dyspnea on activities of daily living (ADL), influence of fatigue on $\mathrm{ADL}$, and change in $\mathrm{ADL}$ in comparison to the period prior to the disease. A partial score is calculated for each domain, ranging from 0 to 100 , and a total score sums up the 3 domains for a maximum score of 300 , with higher values indicating worse functional status. ${ }^{27,29,30}$

The COPD Assessment Test (CAT) is composed of 8 items scored from 0 to 5 and is used to assess the impact of the disease on health status. Scores of $0-10$ represented no impact, 11-20 mild impact, 21-30 moderate impact, and $31-40$ high impact. The total score varies ranges from 0 to 40 , with higher values indicating worse health status. ${ }^{30-32}$

\section{Statistical Analysis}

Normality in data distribution was verified with the Shapiro-Wilk test, and results were described as mean \pm $\mathrm{SD}$ or median and interquartile range. All variables were correlated with MVV and $\mathrm{FEV}_{1}$ with using the Spearman correlation coefficient and, for the variables that presented significant correlations, multivariate linear regression models were used to verify the predictors of each clinical outcome, taking into consideration $\mathrm{MVV}, \mathrm{FEV}_{1}$, and the anthropometric variables of age, gender, weight, and height (as a way to take into account possible confounding factors). ${ }^{33}$ The software used for analysis were SPSS 22.0 (IBM, Armonk, New York) and GraphPad Prism 6.0 (GraphPad, La Jolla, California). Statistical significance was set as $P<.05$.

\section{Results}

The analysis included data from 157 subjects who, in general, were normal weight to overweight and had moderate to severe air-flow obstruction, decreased inspiratory muscle strength, relatively preserved functional exercise capacity, good functional status, and moderate clinical impact on health status (Table 1). A sub-analysis was performed with data available from 37 individuals regarding static lung volumes evaluated with body plethysmography. The characterization of this sample is also found in Table 1.

Table 2 shows the correlations of MVV and $\mathrm{FEV}_{1}$ with weight, height, comorbidities, BODE index, $\mathrm{P}_{\text {Imax }}, \mathrm{P}_{\text {Emax }}$, 6MWT, lung volumes, dyspnea, functional status, and health status. There were weak to moderate and statistically significant correlations for both MVV and $\mathrm{FEV}_{1}$ with the majority of the outcomes analyzed; the exceptions were total lung capacity, residual volume, and the CAT domains for chest pressure and sleep.

Considering only the magnitude of the correlations, for most of the outcomes MVV was better associated than $\mathrm{FEV}_{1}$ (even if slightly) except for the BODE index and the CAT domains for cough and secretion, which presented slightly higher correlation coefficients with $\mathrm{FEV}_{1}$.

Table 3 shows the results of the linear regressions for 6MWT, $\mathrm{P}_{\text {Imax }}$, and $\mathrm{P}_{\text {Emax }}$. In Table 4, the results of the regression models for $\mathrm{mMRC}$, PFSDQ- $\mathrm{m}$, and CAT are presented. These data indicate that MVV appears to be an independent predictor of almost all of the analyzed outcomes, unlike $\mathrm{FEV}_{1}$.

\section{Discussion}

Both traditionally and currently, $\mathrm{FEV}_{1}$ is the most commonly used pulmonary function variable for classification of disease severity and as a predictor of prognosis in patients with COPD. Our results indicate that MVV correlates equally or better than $\mathrm{FEV}_{1}$ with outcomes of dyspnea, exercise capacity, functional status, and health status in subjects with COPD, and MVV is a predictor of variation in most of these outcomes in regression models. The explanation for these results may be related to the fact 
Table 1. Subject Characteristics

\begin{tabular}{|c|c|c|c|}
\hline Variables & Values & Variables & Values \\
\hline Male/female, $n(\%)$ & $82(52) / 75(48)$ & $\mathrm{RV}, \%$ predicted & $156(129-220)$ \\
\hline Age, y & $66(61-73)$ & Inspiratory capacity/TLC $(n=37)$ & $38(32-44)$ \\
\hline Weight, kg & $69(55-79)$ & $\mathrm{RV} / \mathrm{TLC}(n=37)$ & $52(46-60)$ \\
\hline Height, m & $1.5(1.53-1.67)$ & $\mathrm{P}_{\operatorname{Imax}}, \mathrm{cm} \mathrm{H}_{2} \mathrm{O}$ & $65(50-80)$ \\
\hline Body mass index, $\mathrm{kg} / \mathrm{m}^{2}$ & $27(22-31)$ & $\mathrm{P}_{\text {Imax }}, \%$ predicted & $75(56-90)$ \\
\hline Comorbidities, $n(n=144)$ & $1(0-2)$ & $\mathrm{P}_{\mathrm{Emax}}, \mathrm{cm} \mathrm{H}_{2} \mathrm{O}$ & $95(75-123)$ \\
\hline Comorbidities, S/N (\%) & $90(62) / 54(38)$ & $\mathrm{P}_{\text {Emax }}, \%$ predicted & $103(85-126)$ \\
\hline GOLD I/II/III/IV & $1 / 68 / 57 / 31$ & $6 \mathrm{MWD}, \mathrm{m}$ & $465(410-513)$ \\
\hline BODE Index & $4(2-5)$ & $6 \mathrm{MWD}, \%$ predicted & $86(76-96)$ \\
\hline FVC, L & $2.2(1.7-2.9)$ & mMRC & $3(1-3)$ \\
\hline FVC, $\%$ predicted & $72(55-84)$ & PFSDQ-m Dyspnea & $11(5-20)$ \\
\hline $\mathrm{FEV}_{1}, \mathrm{~L}$ & $1.10(0.81-1.55)$ & PFSDQ-m Fatigue & $10(3-8)$ \\
\hline $\mathrm{FEV}_{1}, \%$ predicted & $46(33-57)$ & PFSDQ-m Activities & $10(3-23)$ \\
\hline $\mathrm{FEV}_{1} / \mathrm{FVC}, \%$ & $52(42-62)$ & PFSDQ-m Total $(n=65)$ & $34(14-57)$ \\
\hline $\mathrm{MVV}, \mathrm{L} / \mathrm{min}$ & $42(27-59)$ & CAT Cough & $2(1-3)$ \\
\hline MVV, $\%$ predicted & $42(27-55)$ & CAT Phlegm & $2(1-4)$ \\
\hline Estimated MVV, L/min & $57(46-74)$ & CAT Chest tightness & $0(0-2)$ \\
\hline MVV index & $0.9(0.8-1.1)$ & CAT Breathlessness & $3(2-5)$ \\
\hline TLC, $\mathrm{L}(n=37)$ & $6.85(5.90-7.50)$ & CAT ADL Limitation & $2(0-4)$ \\
\hline TLC, $\%$ predicted & $121(110-135)$ & CAT Confidence & $0(0-3)$ \\
\hline Inspiratory capacity, $\mathrm{L}(n=37)$ & $2.62(2.03-3.23)$ & CAT Sleep & $0(0-2)$ \\
\hline Inspiratory capacity, $\%$ predicted & $117(94-129)$ & CAT Energy & $2(0-3)$ \\
\hline $\mathrm{RV}, \mathrm{L}(n=37)$ & $3.57(2.62-4.59)$ & CAT Total $(n=76)$ & $13(7-19)$ \\
\hline
\end{tabular}

Values are presented as median (interquartile range) unless otherwise noted. $n=157$ unless otherwise noted.

GOLD $=$ Global Initiative for Chronic Obstructive Lung Disease; $B O D E=$ body mass index, air-flow obstruction, dyspnea, exercise capacity; $\mathrm{MVV}=$ maximum voluntary ventilation; $\mathrm{P}_{\mathrm{Imax}}=$ maximum inspiratory pressure; $\mathrm{P}_{\mathrm{Emax}}=$ maximum expiratory pressure; $6 \mathrm{MWD}=6$-min walk distance; $\mathrm{TLC}=$ total lung capacity; $\mathrm{RV}=$ residual volume; $\mathrm{mMRC}=$ modified version of the Medical Research Council scale; PFSDQ-m = Pulmonary Functional Status and Dyspnea Questionnaire modified version; CAT $=$ COPD Assessment Test; ADL $=$ activities of daily living.

that, while $\mathrm{FEV}_{1}$ basically reflects air flow limitation, MVV also reflects the available ventilatory reserve to respond to an increasing physiological demand during exertion. $^{7-9}$

A study by Rocha et al $^{12}$ assessed the diaphragmatic mobility of 25 subjects with COPD and compared it with that of 25 matched controls. The authors reported reduced diaphragmatic mobility in subjects with COPD, as well as strong correlations of diaphragmatic mobility with inspiratory capacity $(r=0.81)$ and with MVV $(r=0.76)$. This suggests that the change in diaphragmatic mobility in patients with COPD is more associated with hyperinflation and with ventilatory capacity than with the obstruction itself, and consequently also more related to the sensation of dyspnea.

Our results also indicate moderate positive correlations between MVV and inspiratory capacity $(r=0.67)$ and inspiratory capacity/total lung capacity $(r=0.48)$, in addition to moderate negative correlations with the mMRC scale ( $\mathrm{r}=-0.56)$ and the PFSDQ-m dyspnea domain $(r=-0.44)$. These values reflect the association of better respiratory mechanics and endurance with lower hyperinflation and less dyspnea sensation.
Yamaguti et $\mathrm{al}^{14}$ reported a stronger correlation between decreased diaphragmatic mobility and air trapping (ie, residual volume/total lung capacity; $r=-0.76$ ) than with hyperinflation (inspiratory capacity; $r=0.63$ ). Our results, in addition to showing a stronger association between hyperinflation and ventilatory capacity, also indicate a moderate negative correlation of MVV with the residual volume/total lung capacity ratio $(\mathrm{r}=-0.56)$, which reflects air trapping.

Pitta et $a l^{10}$ reported that energy expenditure evaluated in daily life with a physical activity monitor correlates better with MVV $(r=0.52)$ than with $\operatorname{FEV}_{1}(r=0.37)$. In addition, Cavalheri et $\mathrm{al}^{11}$ assessed the energy expenditure of individuals with COPD during ADL simulations and also reported a better correlation of this outcome with MVV $(r=0.50)$ in comparison to $\mathrm{FEV}_{1}(\mathrm{r}=0.30)$ and FVC. These results indicate that MVV may reflect the capacity of response to increased respiratory demands and, consequently, also indicate its influence on the physical activity levels of these patients. Our results corroborate and complement these findings, presenting moderate and significant correlations of MVV with the 6MWT, which is already established as an independent predictor 


\section{MaXimum Voluntary Ventilation and Clinical Outcomes in COPD}

Table 2. Correlations of Clinical Outcomes With MVV and FEV

\begin{tabular}{lccccccccc}
\hline \multicolumn{1}{c}{ Outcomes } & MVV, L/min & $P$ & $\mathrm{FEV}_{1}, \mathrm{~L}$ & $P$ & Outcomes & $\mathrm{MVV}, \mathrm{L} / \mathrm{min}$ & $P$ & $\mathrm{FEV}, \mathrm{L}$ & $P$ \\
\hline Weight, $\mathrm{kg}$ & 0.38 & $<.001$ & 0.38 & $<.001$ & PFSDQ-m Dyspnea & -0.44 & $<.001$ & -0.43 & $<.001$ \\
Height, $\mathrm{m}$ & 0.31 & $<.001$ & 0.31 & $<.001$ & PFSDQ-m Fatigue & -0.35 & .004 & -0.30 & .01 \\
BODE Index & -0.73 & $<.001$ & -0.75 & $<.001$ & PFSDQ-m Activities & -0.30 & .01 & -0.25 & .044 \\
Comorbidities & -0.25 & .003 & -0.19 & .02 & PFSDQ-m Total & -0.40 & .001 & -0.36 & .003 \\
$\mathrm{P}_{\text {Imax }}, \mathrm{cm} \mathrm{H} \mathrm{H}_{2} \mathrm{O}$ & 0.40 & $<.001$ & 0.31 & $<.001$ & CAT Cough & -0.30 & .01 & -0.31 & .007 \\
$\mathrm{P}_{\text {Emax }}, \mathrm{cm} \mathrm{H}_{2} \mathrm{O}$ & 0.34 & $<.001$ & 0.28 & $<.001$ & CAT Phlegm & -0.33 & .004 & -0.34 & .003 \\
6MWD, $\mathrm{m}$ & 0.50 & $<.001$ & 0.46 & $<.001$ & CAT Chest tightness & -0.14 & .21 & -0.12 & .33 \\
TLC, $\mathrm{L}(n=37)$ & 0.24 & .15 & 0.28 & .09 & CAT Breathlessness & -0.46 & $<.001$ & -0.41 & $<.001$ \\
Inspiratory capacity, L $(n=37)$ & 0.67 & $<.001$ & 0.65 & $<.001$ & CAT ADL limitation & -0.50 & $<.001$ & -0.44 & $<.001$ \\
RV, L $(n=37)$ & -0.09 & .59 & -0.03 & .83 & CAT Confidence & -0.47 & $<.001$ & -0.36 & .001 \\
Inspiratory capacity/TLC $(n=37)$ & 0.48 & .02 & 0.45 & .05 & CAT Sleep & -0.07 & .52 & -0.09 & .042 \\
RV/TLC $(n=37)$ & -0.56 & $<.001$ & -0.53 & .01 & CAT Energy & -0.29 & .01 & -0.28 & .02 \\
mMRC & -0.56 & $<.001$ & -0.50 & $<.001$ & CAT Total & -0.54 & $<.001$ & -0.49 & $<.001$
\end{tabular}

MVV = maximum voluntary ventilation; $\mathrm{BODE}=$ body mass index, air-flow obstruction, dyspnea, exercise capacity; $\mathrm{P}_{\mathrm{Imax}}=$ maximum inspiratory pressure; $\mathrm{P}_{\mathrm{Emax}}=$ maximum expiratory pressure; $6 \mathrm{MWD}=6$ - $\mathrm{min}$ walk distance; TLC $=$ total lung capacity; RV $=$ residual volume; $\mathrm{mMRC}=$ modified version of the Medical Research Council scale; PFSDQ- $\mathrm{m}=$ Pulmonary Functional Status and Dyspnea Questionnaire modified version; $\mathrm{CAT}=\mathrm{COPD}$ Assessment Test; $\mathrm{ADL}=$ activities of daily living

Table 3. Multiple Linear Regression Analysis for Respiratory Muscle Strength and Functional Exercise Capacity

\begin{tabular}{|c|c|c|c|c|}
\hline & Nonstandardized Coefficient $\beta$ (95\% CI) & $P$ & $\mathrm{r}^{2}$ Adjusted, $\%$ & $\mathrm{r}^{2}$ Adjusted, $\%$ \\
\hline \multicolumn{5}{|l|}{ 6-min walk test } \\
\hline Constant & $662.35(550-774)$ & $<.001$ & & \\
\hline MVV, L/min & $2.06(1.54-2.57)$ & $<.001$ & 23 & 23 \\
\hline Age, y & $-3.16(-4.57$ to -1.76$)$ & $<.001$ & 30 & 29 \\
\hline Body mass index, $\mathrm{kg} / \mathrm{m}^{2}$ & $-3.41(-5.35$ to 1.45$)$ & .001 & 35 & 34 \\
\hline \multicolumn{5}{|l|}{$\mathrm{P}_{\operatorname{Imax}}$} \\
\hline Constant & $90.26(61.35-119.18)$ & $<.001$ & & \\
\hline $\mathrm{MVV}, \mathrm{L} / \mathrm{min}$ & $0.40(0.25-0.56)$ & $<.001$ & 15 & 14 \\
\hline Age, y & $-0.64(-1.06$ to -0.21$)$ & .003 & 20 & 19 \\
\hline \multicolumn{5}{|l|}{$P_{\text {Emax }}$} \\
\hline Constant & $122.67(78-167)$ & $<.001$ & & \\
\hline $\mathrm{MVV}, \mathrm{L} / \mathrm{min}$ & $0.84(0.41-1.27)$ & $<.001$ & 17 & 17 \\
\hline Gender & $27.12(17.31-36.43)$ & $<.001$ & 26 & 25 \\
\hline Age, y & $-1.20(-1.76$ to -0.63$)$ & $<.001$ & 33 & 32 \\
\hline Body mass index, $\mathrm{kg} / \mathrm{m}^{2}$ & $1.18(0.41-1.95)$ & .003 & 37 & 35 \\
\hline $\mathrm{FEV}_{1}, \mathrm{~L}$ & $-22.47(-41.83$ to 3.11$)$ & .02 & 39 & 37 \\
\hline
\end{tabular}

of mortality in COPD and is well associated with the levels of physical activity in daily life in this population. ${ }^{34,35}$ Furthermore, the correlations with respiratory muscle strength reinforce MVV as a measure of the respiratory system broader than just the degree of air flow obstruction by $\mathrm{FEV}_{1}$. In this way, the associations described in this study support the usefulness of MVV as a possible marker of impairment caused by the disease. Thus, our results reinforce the importance of this test in the comprehensive evaluation of lung function to help assess the impact of physical and functional limitation caused by lung disease.
Dugan and Monroe ${ }^{32}$ reported improvement in MVV after a pulmonary rehabilitation program composed of aerobic exercise and upper limb strength exercises, whereas $\mathrm{FEV}_{1}$ did not improve significantly. Dugan and Monroe ${ }^{32}$ also reported that, after pulmonary rehabilitation, there was no improvement in quality of life of subjects with COPD compared to a control group that received usual care, and the authors suggested the hypothesis that pulmonary rehabilitation promotes the improvement of respiratory muscle strength and endurance, leading to a greater sense of comfort for the individuals in the execution of their daily activities with consequent better perception of quality of life. 
Table 4. Multiple Linear Regression Analysis for Dyspnea, Functional Status, and Health Status

\begin{tabular}{|c|c|c|c|c|c|}
\hline & & Nonstandardized Coefficient $\beta$ (95\% CI) & $P$ & $\mathrm{r}^{2}$ Partial, $\%$ & $\mathrm{r}^{2}$ Adjusted, $\%$ \\
\hline \multirow[t]{2}{*}{ mMRC } & Constant & $3.54(3.18-3.90)$ & $<.001$ & & \\
\hline & $\mathrm{MVV}, \mathrm{L} / \mathrm{min}$ & $-0.03(-0.03$ to -0.02$)$ & $<.001$ & 28 & 28 \\
\hline \multirow[t]{3}{*}{ PFSDQ-m Dyspnea } & Constant & $59.43(37.05-81.82)$ & $<.001$ & & \\
\hline & $\mathrm{MVV}, \mathrm{L} / \mathrm{min}$ & $-0.19(-0.31$ to -0.07$)$ & .002 & 27 & 24 \\
\hline & Age, y & $-0.55(-0.88$ to -0.23$)$ & .001 & 14 & 12 \\
\hline \multirow[t]{3}{*}{ PFSDQ-m Fatigue } & Constant & $44.43(19.86-69)$ & .001 & & \\
\hline & $\mathrm{MVV}, \mathrm{L} / \mathrm{min}$ & $-0.15(-0.28$ to -0.03$)$ & .02 & 8 & 7 \\
\hline & Age, y & $-0.37(-0.73$ to -0.02$)$ & .039 & 14 & 11 \\
\hline \multirow[t]{3}{*}{ PFSDQ-m Activities } & Constant & $64.13(32.02-96.25)$ & $<.001$ & & \\
\hline & $\mathrm{MVV}, \mathrm{L} / \mathrm{min}$ & $-0.17(-0.34$ to -0.01$)$ & .041 & 15 & 13 \\
\hline & Age, y & $-0.62(-1.08$ to -0.15$)$ & .01 & 9 & 8 \\
\hline \multirow[t]{3}{*}{ PFSDQ-m Total } & Constant & $168(94.77-241.24)$ & $<.001$ & & \\
\hline & $\mathrm{MVV}, \mathrm{L} / \mathrm{min}$ & $-0.52(-0.91$ to -0.14$)$ & .008 & 19 & 17 \\
\hline & Age, y & $-1.55(-2.62$ to -0.48$)$ & .005 & 12 & 10 \\
\hline \multirow[t]{2}{*}{ CAT Cough } & Constant & $3.17(2.40-3.93)$ & $<.001$ & & \\
\hline & $\mathrm{MVV}, \mathrm{L} / \mathrm{min}$ & $-0.22(-0.038$ to -0.007$)$ & .004 & 10 & 10 \\
\hline \multirow[t]{2}{*}{ CAT Phlegm } & Constant & $3.80(2.77-4.85)$ & $<.001$ & & \\
\hline & $\mathrm{MVV}, \mathrm{L} / \mathrm{min}$ & $-1.28(-2.08$ to -0.47$)$ & .002 & 12 & 11 \\
\hline \multirow[t]{3}{*}{ CAT Shortness of breath } & Constant & $9.39(6.52-12.27)$ & $<.001$ & & \\
\hline & $\mathrm{MVV}, \mathrm{L} / \mathrm{min}$ & $-0.32(-0.47$ to -0.02$)$ & $<.001$ & 17 & 16 \\
\hline & Age, y & $-0.07(-0.11$ to -0.03$)$ & .001 & 28 & 26 \\
\hline \multirow[t]{3}{*}{ CAT ADL limitation } & Constant & $8.58(5.28-11.89)$ & $<.001$ & & \\
\hline & $\mathrm{MVV}, \mathrm{L} / \mathrm{min}$ & $-0.04(-0.06$ to -0.02$)$ & $<.001$ & 22 & 21 \\
\hline & Age, y & $-0.07(-0.11$ to -0.02$)$ & .005 & 30 & 28 \\
\hline \multirow[t]{3}{*}{ CAT Confidence } & Constant & $7.08(3.94-10.21)$ & .001 & & \\
\hline & $\mathrm{MVV}, \mathrm{L} / \mathrm{min}$ & $-0.04(-0.05$ to -0.02$)$ & $<.001$ & 19 & 18 \\
\hline & Age, y & $-0.06(-0.11$ to -0.02$)$ & .006 & 27 & 25 \\
\hline \multirow[t]{2}{*}{ CAT Energy } & Constant & $2.78(1.91-3.65)$ & $<.001$ & & \\
\hline & $\mathrm{MVV}, \mathrm{L} / \mathrm{min}$ & $-0.02(-0.04$ to -0.01$)$ & .02 & 8 & 7 \\
\hline \multirow[t]{3}{*}{ CAT Total } & Constant & $42.76(28.15-57.37)$ & $<.001$ & & \\
\hline & $\mathrm{MVV}, \mathrm{L} / \mathrm{min}$ & $-0.20(-0.28$ to -0.13$)$ & $<.001$ & 26 & 25 \\
\hline & Age, y & $-0.28(-0.49$ to -0.07$)$ & .01 & 33 & 31 \\
\hline
\end{tabular}

$\overline{\mathrm{mMRC}}=$ modified version of the Medical Research Council scale; MVV = maximum voluntary ventilation; PFSDQ-m = Pulmonary Functional Status and Dyspnea Questionnaire, modified version; $\mathrm{CAT}=\mathrm{COPD}$ Assessment Test; $\mathrm{ADL}=$ activities of daily living.

This study supports this hypothesis in that mMRC, PFSDQ-m, and CAT scores correlated better with MVV than with $\mathrm{FEV}_{1}$.

The improvement of MVV (and not necessarily $\mathrm{FEV}_{1}$ ) in the study by Dugan and Monroe ${ }^{32}$ may reflect a patient's improvement in their daily life after pulmonary rehabilitation, allowing less physical limitation due to dyspnea, greater functional reserve, improved performance on ADL and a better self-reported quality of life. These findings may contribute to the understanding of the disease complexity and promote improvement on the way the disease impacts patients with COPD. However, these assumptions are hypothetical and must be proven in longitudinal studies.

The use of 2 different devices to perform spirometry in this study could be considered a limitation. However, we believe that this does not influence the results because the technique used was the same for both groups, strictly following the test standardization proposed by international guidelines. ${ }^{15,19,21,23}$ Furthermore, an adequate effort by all subjects in the MVV maneuver can be ascertained by the very good MVV index in the whole sample (Table 1). Another limitation is the fact that the sample had only one GOLD I subject and, in general, the subjects presented preserved functional exercise capacity and good functional status. This may hinder the generalization of these results for patients with mild disease.

\section{Conclusions}

Our results indicate that MVV correlates well with clinical outcomes in COPD, reflecting more widely the ventilatory dysfunction beyond chronic obstruction. In addition, MVV proved to be a better predictor of functional exercise 


\section{Maximum Voluntary Ventilation and Clinical Outcomes in COPD}

capacity, inspiratory muscle strength, dyspnea, functional status, and health status than $\mathrm{FEV}_{1}$ in this population. Therefore, it is recommended that this test must be integrated into clinical practice and research assessments, while the search for further evidence and standardization of the test should be encouraged.

\section{ACKNOWLEDGMENTS}

We thank all of the members of the Laboratory of Research in Pulmonary Physiotherapy for their support in data collection, study development, and analysis.

\section{REFERENCES}

1. World Health Organization. Chronic respiratory disease: burden of COPD. Available at: https://www.who.int/respiratory/copd/burden/en. Accessed July 29, 2020

2. Jardim JR, Oliveira JC, Nascimento O. II Consenso Brasileiro sobre Doença Pulmonar Obstrutiva Crônica (DPOC). [II Brazilian Consensus on Chronic Obstructive Pulmonary Disease (COPD)]. J Bras Pneumol 2004;30 (Suppl 5):S1-S42.

3. Singh D, Anzueto A, Barnes PJ, Bourbeau J, Celli BR, Criner GJ, et al. Global Strategy for the Diagnosis, Management, and Prevention of Chronic Obstructive Lung Disease: The GOLD Science Committee Report 2019. Available at: www.goldcopd.org. Accessed February 23, 2019.

4. Lopes AJ, de Melo PL. Brazilian studies on pulmonary function in COPD patients: what are the gaps? Int J Chron Obstruct Pulmon Dis 2016; 11:1553-1567.

5. Moreira GL, Gazzotti MR, Manzano BM, Nascimento O, PerezPadilla R, Menezes AM, et al. Incidence of chronic obstructive pulmonary disease based on three spirometric diagnostic criteria in Sao Paulo, Brazil: a nine-year follow-up since the PLATINO prevalence study. Sao Paulo Med J 2015;133(3):245-251.

6. Lim KE, Kim SR, Kim HK, Kim SR. Symptom Clusters and quality of life in subjects with COPD. Respir Care 2017;62(9):1203-1211.

7. Ofir D, Laveneziana P, Webb KA, Lam YM, O'Donnell DE. Mechanisms of dyspnea during cycle exercise in symptomatic patients with GOLD stage I chronic obstructive pulmonary disease. Am J Respir Crit Care Med 2008;177(6):622-629.

8. Barusso MS, Gianjoppe-Santos J, Basso-Vanelli RP, Regueiro EM, Panin JC, Di Lorenzo VA. Limitation of activities of daily living and quality of life based on COPD combined classification. Respir Care 2015;60(3):388-398

9. Pereira EDB, Alcantara M, Medeiros M, Mota R. Influence of respiratory function parameters on the quality of life of COPD patients. J Bras de Pneumol 2009;35(8):7.

10. Pitta F, Takaki MY, Oliveira NH, Sant'anna TJ, Fontana AD, Kovelis $\mathrm{D}$, et al. Relationship between pulmonary function and physical activity in daily life in patients with COPD. Resp Med 2008;102(8):12031207.

11. Cavalheri V, Hill K, Donaria L, Camillo CA, Pitta F. Maximum voluntary ventilation is more strongly associated with energy expenditure during simple activities of daily living than measures of airflow obstruction or respiratory muscle strength in patients with COPD. Chron Respir Dis 2012;9(4):239-240.

12. Rocha FR, Brüggemann AK, Francisco DS, Medeiros CS, Rosal D, Paulin E. Diaphragmatic mobility: relationship with lung function, respiratory muscle strength, dyspnea, and physical activity in daily life in patients with COPD. J Bras Pneumol 2017;43(1):32-37.
13. Souza RMP, Cardim AB, Maia TO, Rocha LG, Bezerra SD, Marinho P. Inspiratory muscle strength, diaphragmatic mobility, and body composition in chronic obstructive pulmonary disease. Physiother Res Int 2019;24(2):e1766.

14. Yamaguti WPS, Paulin E, Shibao S, Chammas MC, Salge JM, Ribeiro $\mathrm{M}$, et al. Air trapping: the major factor limiting diaphragm mobility in chronic obstructive pulmonary disease patients. Respirology 2008;13 (1): $138-144$

15. Miller MR, Hankinson J, Brusasco V, Burgos F, Casaburi R, Coates A, et al. Standardisation of spirometry. Eur Respir J 2005;26(2):319338.

16. Dillard TA, Hnatiuk OW, McCumber TR. Maximum voluntary ventilation: spirometric determinants in chronic obstructive pulmonary disease patients and normal subjects. Am Rev Respir Dis 1993;147(4): 870-875.

17. Polkey MI, Kyroussis D, Hamnegard CH, Mills GH, Hughes PD, Green M, Moxham J. Diaphragm performance during maximal voluntary ventilation in chronic obstructive pulmonary disease. Am J Respir Crit Care Med 1997;155(2):642-648.

18. Pellegrino R, Viegi G, Brusasco V, Crapo RO, Burgos F, Casaburi R, et al. Interpretative strategies for lung function tests. Eur Respir J 2005;26(5):948-968.

19. Pereira C. Diretrizes para testes de função pulmonar: espirometria. J Bras de Pneumol 2002;28(3):82.

20. Pereira CAC, Rodrigues SC. New reference values for forced spirometry in white adults in Brazil. J Bras de Pneumol 2007;33(10).

21. Wanger J, Clausen JL, Coates A, Pedersen OF, Brusasco V, Burgos F, et al. Standardisation of the measurement of lung volumes. Eur Respir J 2005;26(3):511-522.

22. Black LF, Hyatt RE. Maximal respiratory pressures: normal values and relationship to age and sex. Am Rev Respir Dis 1969;99(5):8.

23. Souza RB. Pressões respiratórias estáticas máximas. J Bras de Pneumol 2002;28(3):11.

24. Neder JA, Andreoni S, Lerario MC, Nery LE. Reference values for lung function tests. II. Maximal respiratory pressures and voluntary ventilation. Braz J Med Biol Res 1999;32(6):719-727.

25. Holland AE, Spruit MA, Troosters T, Puhan MA, Pepin V, Saey D, et al. An official European Respiratory Society/American Thoracic Society technical standard: field walking tests in chronic respiratory disease. Eur Respir J 2014;44(6):1428-1446.

26. Britto RR, Probst VS, de Andrade AF, Samora GA, Hernandes NA, Marinho PE, et al. Reference equations for the six-minute walk distance based on a Brazilian multicenter study. Braz J Phys Ther 2013; 17(6):556-563.

27. Kovelis D, Probst VS, Lareau SC, Brunetto AF, Pitta F. Validation of the Modified Pulmonary Functional Status and Dyspnea Questionnaire and the Medical Research Council scale for use in Brazilian patients with chronic obstructive pulmonary disease. J Bras de Pneumol 2008;34(12):11.

28. Bestall JC, Paul EA, Garrod R, Garnham R, Jones PW, Wedzicha JA. Usefulness of the Medical Research Council (MRC) dyspnoea scale as a measure of disability in patients with chronic obstructive pulmonary disease. Thorax 1999;54(7):581-586.

29. Lareau SM, Roos PJ, Linda L. Development and testing of the modified version of the Pulmonary Functional Status and Dyspnea Questionnaire (PFSDQ-M). Heart Lung 1998;27(3):10.

30. Silva GPF, Viana CMS, Magalhaes CBA, Pereira E. Portuguese-language version of the COPD Assessment Test: validation for use in Brazil. J Bras de Pneumol 2013;39(4):17.

31. Jones PW, Harding G, Berry P, Wiklund I, Chen WH, Kline Leidy N. Development and first validation of the COPD Assessment Test. Eur Respir J 2009;34(3):648-654.

32. Dugan D, Monroe DA. The effects of 9-week program of aerobic and upper body exercise on the maximal voluntary ventilation of chronic 


\section{MaXimum Voluntary Ventilation and Clinical Outcomes in COPD}

obstructive pulmonary disease patients. J Cardiopulm Rehabil 1995;15 (2): 130-133

33. Schober P, Boer C, Schwarte LA. Correlation coefficients: appropriate use and interpretation. Anesth Analg 2018;126(5):1763-1768.

34. Pitta F, Troosters T, Spruit MA, Probst VS, Decramer M, Gosselink R. Characteristics of physical activities in daily life in chronic obstructive pulmonary disease. Am J Respir Crit Care Med 2005;171(9):972-977.

35. Polkey MI, Spruit MA, Edwards LD, Watkins ML, Pinto-Plata V, Vestbo J, et al. Six-minute-walk test in chronic obstructive pulmonary disease: Minimal clinically important difference for death or hospitalization. Am J Respir Crit Care Med 2013;187(4):382-386. 